\title{
Surfacing - Technologies and Layer Properties (a Review)
}

\author{
Manahil Tongov \\ Faculty of Industrial Technology \\ Technical University of Sofia \\ Sofia, Bulgaria \\ tongov@tu-sofia.bg
}

\begin{abstract}
The overview includes the basic methods for obtaining surface layers: arc surfacing - submerged arc surfacing (SAS), tungsten inert gas arc surfacing (TIGS), metal gas surfacing (MIG/MAG), plasma surfacing (PS); electron beam surfacing (EBS); laser surfacing (LS); electroless cladding (ELC); friction stir surfacing (FSS). Layers are applied on carbon steels, low alloyed steels, highly alloyed steels, aluminium alloys, titanium alloys or ductile cast iron substrates. The data on the additive materials used are provided and data on the hardness and wear resistance of the layers is given.
\end{abstract}

Keywords - surface layers; methods; hardness, wear.

\section{INTRODUCTION}

The application of layers and the modification of the surface of the parts are widely used in various areas of the industry. This review examines various technological processes that allow for a substantial change in surface properties relative to those of the substrate. Emphasis is placed on the resulting hardness and surface wear. The wear resistance data of the layer is generally compared with that of the substrate metal in the application of layers of homogeneous composition. The wear resistance of the layers in which there is a dispersed phase is compared to layers without dispersive phase. The variants, which demonstrates the best results are shown. The hardness data are given in the way they are published by the authors concerned, indicating the maximum values achieved.

\section{TECHNOLOGICAL PROCESSES}

The surfacing technological processes are in most cases close to welding processes. However, there are also technological variants that differ significantly from welding and are not applicable to joint parts. Thus, the thickest layers are obtained by electroslag surfacing (ESS) [1]. In this case, as with submerged arc surfacing (SAS) [5], [6], [7], [19], the layer characteristics are obtained depending on the combination of the components contained in the flux and the additive wire. Typically, the additional wires are solid, but core wires [6], [19] is used also. The components added in the flux which leads to increasing of the hardening phases [2] results in similar effects on hardness and wear resistance. The core wire are widely used in another electric arc processes - TIG [11],
[12] and [13] and MIG/MAG [3], [10], [15], [16], [17] 20]. The solid wires are applicable in the MIG / MAG process [4], [8], [9], [10], [18] too. Additional impacts such as forced gas cooling [4], longitudinal electromagnetic field [10] and post-surfacing electron beam treatment [3] are also used to improve the characteristics of the applied layer. The heat output of the welding arc is also used for remelting of the pre-deposited layer [14]. The plasma arc can also be used to remelt a deposited layer [21] or apply a layer using the powder injected in the plasma arc [22], [23], [24]. In both cases, the surface of the substrate melts, a welding pool is formed, and during on its crystallization the additive materials participate in the formation of the layer and thus determine its properties. When the aim is to obtain intermetallic compounds with the metal of the substrate in the coating, this can be achieved by adding the second metal in the form of a powder [23]. High cooling rates using heat sources with high energy concentration such as electron beam surfacing (EBS) [25], [26], [27], [28] and [29] or laser surfacing (LS) [30] - [39] creates conditions for modifying the surface layer even without the use of filler materials [25] or after a surfacing process has been performed [3], [26]. The electron beam process is also used for sintering [27] of powder mixture to form layers. Laser surfacing is realized in three ways. The first one involves the introduction of powder material into the heated zone [30], [31], [32], [33], the second assumes the remelting of a precoat [35], [36], [37] [39] and the third uses a gaseous medium to introduce the necessary components [34]. Another possibility to produce the layer is electroless cladding (ELC) from a solution and subsequent thermal treating [40], [41], [42]. The specific in this case is that no heating is required for the deposition of the bed, and the thermal treatment is at relatively low temperatures $(2900 \mathrm{C})$. Both in this case and in the friction stir surfacing (FSC) [43], [44], [45], [46], [47], the melting temperatures of the substrate are not reached. Therefore, diffusion processes have a significant effect on the final result. Powders may also be used during friction stir technology [44] and [45].

\section{RESEARCH METHODS}

The methods used to study layers properties can be 
divided into the following main groups. The microstructure is examined by optical (OM) [1], [9], [17], [21], [23], [27], [30], [31], [36] ], [42], [43] and electron microscopy (SEM) [1], [10], [11], [14], [21], [22], [23], [33], [39], [46], [47]. The phase composition is determined by the X-ray diffractometer [18], [23], [27], [31], [33], [36], [39], [45], the transmission diffraction electron microscopy [18] and energy-dispersive X-ray spectroscopy [14], [22], [30], [33], [39]. The X-ray fluorescence method [7] and the atomic emission spectrometer [7] were used to determine the chemical composition. Image analysis is used to determine the relative share of individual components [1].

\section{SUBSTRATE MATERIALS}

In the publications reviewed, the materials used as substrates can be divided into the following main groups: carbon steels [3], [6], [7], [12], [13], [15], [16] 17, 18, $21,25,26,29,36$ and 37; alloyed steels [1], [4], [8], [9], [20], [22], [24], [30], [41] and [42]; highly alloyed steels [5] and [32]; aluminium and aluminium alloys [11], [28], [39], [43], [44] and [45]; titanium and titanium alloys [23], [31], [34] and [35]; ductile cast iron [33] and [40]. The SAS, MIG / MAG, TIG, PST, EBS and LS methods were used to apply the layers to carbon steels. When the substrate is made from alloy steel ESA, MIG / MAG, PST, LS and ELC were used. With a high alloy steel substrate, the SAS and LS methods are listed. The deposition of layers on ductile cast iron is represented by the LS and ELS methods. The TIG, EBS, LS and FSS methods have been used for layers deposited on aluminium or aluminium alloys. To deposit layers over titanium and titanium alloys two methods are presented - PST and LS.

\section{FILLER MATERIALS AND LAYER PROPERTIES}

Highest thickness layers are obtained using electroslag surfacing. The process for depositing high-chromium cast iron on low-alloy steel is described [1]. The chemical composition of the applied layer is shown in Table 1 [1]. The content of vanadium is varied. Rockwell hardness and wear resistant of the applied layer are measured and data (presented as graphics in [1]) is shown into the same table. The results show that hardness and wear resistance have the highest values for vanadium content of $1.5 \mathrm{wt} \%$.

TABLE I

\begin{tabular}{|c|c|c|c|c|c|c|}
\hline \multicolumn{5}{|c|}{$\begin{array}{c}\text { Layer chemical composition, wt\% } \\
\text { (Fe-bal.) }\end{array}$} & \multirow{2}{*}{ HRC } & $\begin{array}{c}\text { Volume } \\
\text { lost, } \\
{\left[\mathbf{m m}^{3}\right]}\end{array}$ \\
\hline $\boldsymbol{C}$ & $\boldsymbol{M n}$ & $\boldsymbol{S i}$ & $\boldsymbol{C r}$ & $\boldsymbol{V}$ & & 220 \\
\hline 3.62 & 2.31 & 0.86 & 19.48 & & 58.5 & 220 \\
\hline 3.59 & 2.25 & 0.68 & 20.19 & 0.83 & 59 & 160 \\
\hline $\mathbf{3 . 5 8}$ & $\mathbf{2 . 0 6}$ & $\mathbf{0 . 6 8}$ & $\mathbf{1 9 . 4 0}$ & $\mathbf{1 . 5 0}$ & $\mathbf{6 1}$ & $\mathbf{8 0}$ \\
\hline 3.56 & 1.91 & 0.64 & 19.57 & 2.32 & 60 & 180 \\
\hline
\end{tabular}

The filler materials used with submerged arc surfacing are shown in Table 2 [5], [7] and [20]. In practice, in all cases, the major alloying elements are C-Mn-Si-Cr-NiMo-V. To increase amount of carbides $\mathrm{B}$ and $\mathrm{Nb}$ are added. Small amounts of cobalt are also registered in [7] and [20]. Filler materials are solid or core wires. The resulting hardness of the specimen surface is also shown in Table 2. In general, it correlates with wear resistance. Experiments with a powder mixture containing ( $\mathrm{wt} \%)$ : $\mathrm{Al}_{2} \mathrm{O}_{3}$ $=21-46.23 ; \mathrm{F}=18-27 ; \mathrm{Na}_{2} \mathrm{O}=8-15 ; \mathrm{K}_{2} \mathrm{O}=0.4-6 ; \mathrm{CaO}$ $=0.7-2.3 ; \mathrm{SiO}_{2}=0.5-2.48 ; \mathrm{Fe}_{2} \mathrm{O}_{3}=2.1-3.27 ; \mathrm{C}=12.5$ $30.2 ; \mathrm{MnO}=0.07-0.9 ; \mathrm{MgO}=0.06-0.9 ; \mathrm{S}=0.09-0.19 ; \mathrm{P}$ $=0.1-0.18$ are carred out [6]. A regression analysis of the obtained results was made and equations for the hardness and wear resistance of the type:

$$
\begin{aligned}
& y=A_{o}+A_{1} C+A_{2} \mathrm{Si}+A_{3} \mathrm{Mn}+A_{4} \mathrm{Cr}+ \\
& +A_{5} \mathrm{Ni}+A_{6} \mathrm{Mo}+A_{7} \mathrm{Co}+A_{8} \mathrm{Al}+A_{9} \mathrm{Cu}+ \\
& +A_{10} \mathrm{H}
\end{aligned}
$$

The values of the coefficients are given in Table 3 .

The method presented in [19] uses two electrode wires for submerged arc surfacing- the first wire is equivalent to steel 30XGCA and second to aluminium alloy AlMg3 [19]. As mentioned, the second wire behind the main arc has a radically different chemical composition. The reached hardness of the layer varies from 28 to 55HRC depend on the conditions of the process - both filler wires ratios and the magnitude of the current.

In MIG / MAG overlaying [3], [9], [14], [15] and [18], core wires are commonly used. Table 4 shows the chemical composition. In [18] the Vickers hardness was also measured. Maximum measured value is 11 [GPa]. The main alloying elements are C-Mn-Si-Cr-Ni. In [14] layers are deposited on an aluminium substrate. Micro particles of $\mathrm{SiC}$ are used to increase wear resistance. Particles are coated with nickel using electroless method in salt (NiSO4 and $\mathrm{NiCl} 2$ ) solutions. In addition, the influence of flux (based on cryolite and three salts - sodium chloride, potassium chloride and magnesium chloride) deposited on the nickel coating was investigated. The results are compared with those obtained by the TIG method [11], where micro and nano $\mathrm{SiC}$ particles were also used. It has been found that wear resistance is highest when using nanoparticles coated with flux. 
TABLE II

\begin{tabular}{|c|c|c|c|c|c|c|c|c|c|c|c|c|c|}
\hline \multicolumn{9}{|c|}{ Chemical composition (Fe-bal.) (wt\%) } & \multirow{2}{*}{$\mathbf{H V}_{30}$} & \multirow{2}{*}{ HRC } & \multicolumn{2}{|c|}{ Wear rate } & \multirow{2}{*}{ Remark } \\
\hline$C$ & $M n$ & Si & $\mathrm{Cr}$ & $\mathrm{Ni}$ & Mo & $V$ & $B$ & $N b$ & & & $m m^{3} /(N . m)$ & $m g / m i n$ & \\
\hline 0.12 & 1.0 & 0.6 & 12 & 2.92 & & & & & 400 & & 0.052 & & filler \\
\hline 0.1 & 1.0 & 0.6 & 12 & 2.5 & 0.8 & 0.15 & & 0.15 & 550 & & 0.032 & & \\
\hline 0.25 & 1.0 & 0.6 & 9 & 0.25 & 2.0 & & & & 600 & & 0.0011 & & \\
\hline 0.3 & 1.0 & 0.6 & 12.2 & & 0.75 & 0.15 & & & 675 & & 0.0014 & & \\
\hline 0.19 & 0.52 & 0.74 & 2.79 & 0.17 & 0.26 & 0.14 & 0.001 & & & 44 & & 0.03 & deposit \\
\hline 0.22 & 0.62 & 0.35 & 2.78 & 0.09 & 0.25 & 0.02 & 0.001 & & & 36 & & 0.04 & \\
\hline 0.27 & 0.68 & 0.49 & 4.61 & 0.36 & 0.42 & 0.01 & 0.001 & & & 48 & & 0.04 & \\
\hline 0.43 & 0.84 & 0.37 & 7.04 & 0.42 & 0.49 & 0.03 & 0.001 & & & 56 & & 0.02 & \\
\hline 0.16 & 0.32 & 0.62 & 0.25 & & 0.11 & 0.19 & 0.003 & & & 37 & & 0.15 & \\
\hline 0.10 & 0.45 & 0.15 & 0.23 & 0.08 & 0.10 & 0.11 & 0.003 & & & 28 & & 0.10 & \\
\hline 0.23 & 0.66 & 0.25 & 0.95 & 0.34 & 0.35 & 0.29 & 0.003 & & & 44 & & 0.12 & \\
\hline
\end{tabular}

TABLE III

\begin{tabular}{|c|c|c|c|c|}
\hline \multirow[t]{3}{*}{$\mathbf{A}_{\mathrm{i}}$} & \multicolumn{2}{|c|}{ Hardness } & \multicolumn{2}{|c|}{ Wear resistance } \\
\hline & with $H$ & with no $H$ & with $\mathrm{H}$ & with no $H$ \\
\hline & & & \multicolumn{2}{|c|}{$.10^{3}$} \\
\hline $\mathrm{A}_{0}$ & 214.819 & 535.343 & 0.260 & 2.005 \\
\hline$A_{1}$ & -163.253 & 168.120 & -0.695 & 1.110 \\
\hline $\mathrm{A}_{2}$ & -307.499 & -276.437 & -0.973 & -0.804 \\
\hline $\mathrm{A}_{3}$ & -353.293 & -890.442 & -0.597 & -3.522 \\
\hline $\mathrm{A}_{4}$ & -21.239 & 6.037 & -0.108 & 0.040 \\
\hline $\mathrm{A}_{5}$ & 33.871 & 108.851 & 0.091 & 0.500 \\
\hline$A_{6}$ & 858.517 & 445.851 & 2.707 & 0.460 \\
\hline $\mathrm{A}_{7}$ & -280.917 & -433.688 & -0.229 & -1.061 \\
\hline $\mathrm{A}_{8}$ & & -1014.594 & & -5.525 \\
\hline $\mathrm{A}_{9}$ & 321.784 & 477.567 & 2.283 & 3.132 \\
\hline $\mathrm{A}_{10}$ & 13.830 & & 0.075 & \\
\hline $\begin{array}{l}\text { Appr. error, } \\
\%\end{array}$ & 0.01 & 0.01 & 10.74 & 0.32 \\
\hline
\end{tabular}

The TIG method is used to apply layers containing nanoscale particles of $\mathrm{Al}_{2} \mathrm{O}_{3}$ and TiCN. Nano powder is fed directly into the low-temperature zone of the welding pool. The method of direct nanoscale particle delivery is compared with the method of melting a precoated layer. The wear is compared to a sample without a nanomodifier. The results obtained show an increase in the wear resistance of the layers with modifier (up to $30 \%$ ) and that direct delivery of the powder in the welding pool gives a better result. The achieved microhardness is up to 350 $\mathrm{HV}_{0.1}$. The use of nanoscale particles of TiN, doped with chromium, as a dispersed phase, has been investigated in [13]. Overlayed layers with and without a nano modifier are compared. It has been found that the use of $\mathrm{TiN}+\mathrm{Cr}$ increases up to 2 times the wear resistance. The hardness reached $282 \mathrm{HV}$.

\begin{tabular}{|c|l|c|c|c|c|c|c|c|c|l|}
\hline \multicolumn{7}{|c|}{ Chemical composition (Fe-bal.) (wt\%) } & \multirow{2}{*}{ Remark } \\
\hline $\boldsymbol{C}$ & $\boldsymbol{M n}$ & $\boldsymbol{S i}$ & $\boldsymbol{C r}$ & $\boldsymbol{N i}$ & $\boldsymbol{M o}$ & $\boldsymbol{V}$ & $\boldsymbol{W}$ & $\boldsymbol{N} \boldsymbol{b}$ & $\boldsymbol{C u}$ & \\
\hline 1.3 & 0.9 & 1.1 & 7.0 & & & & 1.4 & 8.5 & & filler \\
\hline 0.07 & 7.03 & 0.78 & 19 & 8.94 & 0.15 & & & & 0.1 & deposit \\
\hline 0.09 & 5.32 & 0.83 & 14.68 & 6.62 & & & & & & deposit \\
\hline 1.43 & 0.81 & 0.55 & 5.22 & 0.1 & 1.30 & & & 5.85 & & \\
\hline 4.46 & 0.76 & 0.77 & 23.54 & 0.11 & & & & & & \\
\hline 1.4 & & & 7.0 & & & 1.0 & 1.2 & 8.0 & & \\
\hline
\end{tabular}

When plasma surfacing process is used, the filler material is in the form of a powder. It can be fed through the plasma gun or to be pre-applied onto the pad in the form of a paste. Thus, for example, in the use of a powder containing (wt $\%$ ) C-0.9; Si-2 $\div 3$; Cr- $8 \div 10$; B-2.8 $\div$ 3.2 and Fe-bal. a hardness of the $60.6 \mathrm{HRC}$ layer was obtained at the hardness of the 41 HRC matrix [22]. The wear of the layer compared to the substrate in this case is $30 \%$ less. In [24] results were obtained using a nickel based composition containing (wt\%) of F3-2.5; C-0.3; Cr-7; B-2.2 and Ni-bal. The hardness reached in this case is $754 \mathrm{HV}$. In [21] we have shown a hardness of $400 \div 1800 \mathrm{HK}$ using NiCrBSiC filler material. In [23] unalloyed aluminium powder is used and a layer is applied to titanium. The particle size is 75 to 147 [nm]. A TiAl-based intermetallic layer is obtained on the surface. Electron beam processes are mainly used to improve the properties of the applied layer. Using electron beam scan of the applied layer, the hardness increased 1.7 times and the wear resistance was 70 times higher comparing to substrate [25] and [26]. The main reason for this is the change of structure (a cell structure of $20 \div 100 \mu \mathrm{m}$ is obtained) on the surface of the layer due to the high cooling rates. The additive material contained (wt $\%)$ : C-1.3; Mn -0.9; Si-0.3; Cr-7.0; W-1.4; Nb-8.5 and Febal. In [27] the possibility of sintering of pre-compressed powdered samples containing $\mathrm{TiC}$ and $\mathrm{Ti}$ was investigated and the titanium content was (vol.\%) - 50 and 60 . In parallel, mixtures of TiC and $20 \div 50 \%$ nickel based self- 
fluxing alloy was exanimated. These mixtures could be used as a component of a paste applied to the substrate. The ability to obtain a layer of $\mathrm{TiCuN}$ on an aluminium substrate is shown in [28] through process modelling and experimental

verification. The layer was applied by plasma surfacing and subsequent electron beam treatment. Electron beam technology for deposition of layers by surface remelting is described in [29]. The samples was scanned with an electron beam to make specific roughness. On prepared rough surface a paste containing TiN or TiCN is applied. Subsequent remelting of the surface layer was performed. The wear resistance of the layer was $36 \%$ higher than that of the base reference sample without coating.

The materials used for deposition of layers by laser technology are given in table. 5. Various techniques are used to obtain the necessary hardening phases. Thus, for example, to obtain titanium nitride into the surface layer in the $\mathrm{Ti}_{6} \mathrm{Al}_{4} \mathrm{~V}$ substrate, a process is carried out in a pure nitrogen medium [34]. The resulting hardness is in the range $1000 \div 2300 \mathrm{HV}_{0.2}$. A mixture of $\mathrm{Ti}$ and $\mathrm{TiC}$ is introduced directly into the molten metal applying a layer over ductile cast iron [33]. Depending on the process parameters different concentrations of $\mathrm{Ti}$ are obtained in the melt layer from 3.0 to 5.9 and $\mathrm{TiC}-4.8 \div 14.8 \mathrm{vol} \%$. The reached hardness of the layer is $800 \mathrm{HV}_{0.2}$. The wear resistance of the layer is about 10 times higher than that of the substrate. On the same type of substrate $\left(\mathrm{Ti}_{6} \mathrm{Al}_{4} \mathrm{~V}\right)$ using a mixture of $\mathrm{Ti}_{6} \mathrm{Al}_{4} \mathrm{~V}$ and $\mathrm{B}_{4} \mathrm{C}$ is applied a layer by direct feeding of the powder material to the melting zone [31]. The hardness achieved in this case is $480 \mathrm{HV}$. On pure titanium a layer is applied using a graphite powder mixed with polyvinyl alcohol, dried and applied as a paste [35]. Surface is remelted. The achieved hardness of the layer surface is $300 \mathrm{HV}_{0.3}$. Similarly, a graphite powder blended with $\mathrm{Ni}, \mathrm{C}, \mathrm{V}$, and $\mathrm{Ti}$ is applied in the indicated proportions onto a medium carbon substrate [36] and [37]. The hardness of the resulting layer is $800 \mathrm{HV}_{0.3}$. It has been found that the hardness can be increased to $970 \mathrm{HV}_{0.3}$ by increasing the laser beam scanning speed. Powderbased paste [39] is applied to an aluminium substrate and scanned with a laser beam. The hardness of the layer is $500 \mathrm{HV}$. When the layer consists mainly of $\mathrm{Al}_{3} \mathrm{Ti} / \mathrm{TiC}$ its wear resistance increases to 10 times compare to the pad.

When layers are depositing on highly alloyed chromium-nickel steels [32] with the use of nickel and iron-based powders, the Vickers hardness is $460 \mathrm{MPa}$ at the surface of the bed and decreases to $250 \mathrm{MPa}$ at the base metal boundary (layer thickness is $0.5 \mathrm{~mm}$ ).

TABLE V

\begin{tabular}{|l|l|l|}
\hline \multicolumn{1}{|c|}{ Chemical composition $(\mathbf{w t} \%)$} & remark & Ref. \\
\hline $\begin{array}{l}\mathrm{C}-0.2 ; \mathrm{Si}-0.75 ; \mathrm{Cr}-16 ; \mathrm{Ni}-2.5 ; \mathrm{Mo}-0.5 ; \\
\mathrm{B}-1.0 ; \mathrm{Co}-0.5 ; \mathrm{Fe}-\text { bal }\end{array}$ & powder & {$[30]$} \\
\hline $\mathrm{Ti}_{6} \mathrm{Al}_{4} \mathrm{~V}-80 ; \mathrm{B}_{4} \mathrm{C}-20$ & powder & {$[31]$} \\
\hline $\begin{array}{l}\mathrm{C}-0.23 ; \mathrm{Mn}-0.7 ; \mathrm{Si}-0.7 ; \mathrm{Cr}-13 ; \mathrm{Ni}-2.2 ; \mathrm{Fe}- \\
\text { bal }\end{array}$ & powder & {$[32]$} \\
\hline $\begin{array}{l}\mathrm{C}-0.34 ; \mathrm{Mn}-0.6 ; \mathrm{Si}-0.5 ; \mathrm{Cr}-13 ; \mathrm{Ni}-0.3 ; \mathrm{Fe}- \\
\text { bal }\end{array}$ & powder & \\
\hline Fe-3.7; C-0.5; Si-3.1; Cr-15; Ni-bal & powder & \\
\hline
\end{tabular}

\begin{tabular}{|l|l|l|}
\hline Fe-4.9; C-0.7; Si-3.1; Cr-16; Ni-bal & powder & \\
\hline $\mathrm{Ti}+\mathrm{TiC}$ & powder & {$[33]$} \\
\hline $\mathrm{N}$ & gas & {$[34]$} \\
\hline $\mathrm{C}$ - graphite powder & paste & {$[35]$} \\
\hline $\mathrm{C} ; \mathrm{Ni}=8 \mathrm{C} ; \mathrm{V}=4 \mathrm{C} ; \mathrm{Ti}=4 \mathrm{C}$ & paste & {$[36]$} \\
\hline $\mathrm{C} ; \mathrm{Ti}$ & paste & {$[37]$} \\
\hline $\mathrm{Al} ; \mathrm{Ti} ; \mathrm{TiB}_{2} ; \mathrm{TiC} ; \mathrm{SiC}$ & paste & {$[39]$} \\
\hline
\end{tabular}

The deposition of layers by electroless method is realized in [40] $\div$ [42]. The method consists of depositing a nickel layer followed by deposition of a layer containing a hardening phase - TiN or a detonating nano diamond. The particles of the hardening phase have nanoscale values of $4 \div 6 \mathrm{~nm}$. Low alloy steel and ductile cast iron are used as substrates. The hardness reached $720 \mathrm{HV}_{0.3}$ and the wear resistance of the layers containing the hardening phase is up to 10 times higher than the nickel-only coating. Heat treatment $\left(290^{\circ} \mathrm{C} / 6 \mathrm{~h}\right)$ can reduce wear to $36 \%$.

Friction stir surfacing is also used for depositing layers on aluminium alloys [43] $\div$ [45]. The additive material may be in the form of a wire or powder containing a hardening phase such as $\mathrm{SiC}$ or $\mathrm{Al}_{2} \mathrm{O}_{3}$. Using a wire with a composition (wt.\%): $97.5 \mathrm{Al}, 1.87 \mathrm{Mg}, 0.086 \mathrm{Si}, 0.006 \mathrm{Mn}$, $0.009 \mathrm{Cu}, 0.27 \mathrm{Fe}$ and $0.21 \mathrm{Cr}$ a hardness of $85 \mathrm{HV}_{0.2}$ [43] was achieved. When using a hardening phase, wear is reduced to 7 times compare to substrate.

In some of the publications reviewed, there is an indication of the coefficient of friction and its change in the process of the experiment [3] $\div$ [5], [33], [35] and [44] $\div$ [46]. These values varies from 0.12 to 0.75 , and in some cases are averaged only.

\section{CONCLUTIONS}

The technologies used to apply surface layers in the reviewed publications are electroslag surfacing, electric arc methods (MIG/ MAG, TIG, submerged arc and plasma surfacing), beam methods (electron beam and laser surfacing), friction stir electroless surfacing. Steel, aluminum and titanium alloys are used as substrates. The hardness (up to $61 \mathrm{HRC}$ and $2300 \mathrm{HV}$ ) and wear resistance varies over a wide range depending on the process and the filler materials.

\section{REFERENCES}

[1] H. Wang., S. F. Yu, A. R. Khan and A.G. Huang, .,Effects of vanadium on microstructure and wear resistance of high chromium cast iron hardfacing, layer by electroslag surfacing, (2018) Metals, 8 (6), art. no. 458.

[2] N.A. Kozyrev, R. E. Kryukov, A. A. Umanskii, A.R. Mikhno and L. V. Dumova, Investigation and development of welding fluxes with the use of ladle electric-furnace slag and barium-strontium modifier for rolls surfacing, (2018) Izvestiya Ferrous Metallurgy, 61 (4), pp. 274-279

[3] Y. F. Ivanov, V. E. Kormyshev, V. E. Gromov, S. V. Konovalov, E.V. Martusevich, A. D. Teresov and A. P. Semin, The Increase in Wear Resistance of Low Carbon Steel by Flux-Cored Wire Surfacing Followed Be Electron Beam Processing, (2017) IOP Conference Series: Materials Science and Engineering, 253 (1), art. no. 012019

[4] T. Wêgrzyn, J Piwnik, L Wszolek and W. Tarasiuk, Shaft wear af- 
ter surfacing with microjet cooling, (2015) Archives of Metallurgy and Materials, 60 (4), pp. 2625-2630

[5] J. Brezinová, A. Guzanová, P. Maruschak and D. Lorincová, Study of wear processes of weld clads, (2014) Acta Metallurgica Slovaca, 20 (2), pp. 167-176

[6] A.I. Gusev, N.A. Kozyrev, I.V. Osetkovskiy, R.E., Kryukov and O.A. Kozyreva, Quality of Metal Deposited Flux Cored Wire with the System Fe-C-Si-Mn-Cr-Mo-Ni-V-Co, (2017) IOP Conference Series: Materials Science and Engineering, 253 (1), art. no. 012008

[7] A. I. Gusev, N.V. Kibko, N.A. Kozyrev, M.V. Popova and I. V. Osetkovsky, A study on the properties of the deposited metal by flux cored wires 40GMFR and 40H3G2MF, (2016) IOP Conference Series: Materials Science and Engineering, 150 (1), art. no. 012033

[8] S. Song, Y. Liu, Q. Ke and Y. Shen,.., Overlaying welding technology and performance of axle tube remanufacturing, (2013) Advances in Manufacturing, 1 (2), pp. 143-150.

[9] M. Lomozik and J. Adamiec, Impact of heat treatment on microstructure of steel 30X padded with wire G18 8Mn, (2012) IOP Conference Series: Materials Science and Engineering, 35 (1), art. no. 012021

[10] J. Luo, F. Li and X. Wang, Microstructure and mechanical properties of overlaying specimens in GMAW hybrid an additiona longitudinal electromagnetic field, (2011) Yosetsu Gakkai Ronbunshu/Quarterly Journal of the Japan Welding Society, 29 (3), pp. $76 \mathrm{~s}-80 \mathrm{~s}$

[11] R. Dimitrova R, M. Kandeva and V. Kamburov, Mechanical and tribological characteristics of TIG hardfaced dispersive layer by reinforced with particles extruded aluminium, JournalTribology in Industry, (2017), Vol.39, (1), pp 9-19, .

[12] T. Petrov, P. Tashev and M. Kandeva, Wear resistance of suface layers modified with $\mathrm{Al} 2 \mathrm{O} 3$ and $\mathrm{TiCN}$ nanopowders weld overlaid using tig and itig methods, Journal of the Balkan Tribologica Association 2016, SciBulCom Ltd., vol. 22, No 1, №1136, ISSN 1310-4772,

[13] P. Tashev, R. Lazarova, M. Kandeva, R. Petrov and V. Manolov, "Tungsten Inert Gas Weld Overlay using Nano-sized TiN Powder", JOURNAL OF THE BALKAN TRIBOLOGICAL ASSOCIATION, Vol. 22, No 3, 2238-2254

[14] V. Kamburov, R. Dimitrova and M. Kandeva, Introduction of nickel coated silicon carbide particles in aluminum metal matrix hardfaced by MIG/TIG processes on precoated flux layer. Tribology in Industry 40(1), pp. 73-80

[15] F. Huang, W. Peng, Y. Zhao and Z. Ren, Push-off test for measuring the bonding property between surfacing layers and steel base metal and its application, (2017) ISIJ International, 57 (4), pp. 723-729.

[16] V. E. Kormyshev, Y.F. Ivanov, V.E. Gromov, S.V. Konovalov and A.D. Teresov, Surface nanohardness of wear resistant surfacing irradiated by electron beam, (2017) Izvestiya Ferrous Metallurgy, 60 (4), pp. 304-309.

[17] R. Bęczkowski and M. Gucwa1, Defects Appearing in the Surfacing Layers of Abrasion Resistant, (2016) Archives of Foundry Engineering, 16 (4), pp. 23-28.

[18] S.V. Konovalov, V.E. Kormyshev, S.A. Nevskii, Y.F. Ivanov and V.E. Gromov, Formation Wear Resistant Coatings on Martensite Steel Hardox 450 by Welding Methods, (2016) IOP Conference Series: Materials Science and Engineering, 142 (1),

[19] D.N. Makeev, O.V. Zakharov, A.N. Vinogradov and A.V. Kochetkov, Modification of Surface Layers by Surfacing Intermetallic Coatings with Variable Properties, (2016) IOP Conference Series: Materials Science and Engineering, 116 (1), art. no. 012023 ,

[20] A.I. Gusev, N.V. Kibko, M.V. Popova, N.A. Kozyrev and I.V. Osetkovskii, Surfacing of details of mining equipment by powder wires of $\mathrm{C}-\mathrm{Si}-\mathrm{Mn}-\mathrm{Mo}-\mathrm{V}-\mathrm{B}$ AND C $-\mathrm{Si}-\mathrm{Mn}-\mathrm{Cr}-\mathrm{Mo}$ -V systems, (2017) Izvestiya Ferrous Metallurgy, 60 (4), pp. 318323

[21] T. Simeonova, M. Tongov and G. Avdeev, Microstructure and properties of NiCrBSiC overlay coatings deposited by plasma scanning process, WIT Transactions on the Built Environment Volume 137, 2014, Pages 553-564 International Conference on High Performance and Optimum Design of Structures and Materials, HPSM/OPTI 2014; Ostend; Belgium; 9 June 2014 through 11 June 2014; Code 105905 , ISSN: 1743-3509, DOI 10.2495/ HPSM140511

[22] L. Song, J. Guo, M.A. Xiaolei and J Zhao, Research on Microstructure and Wear Resistance of Fe-Based Hardfacing Layer Using Plasma Surfacing Technology, (2018) IOP Conference Series: Materials Science and Engineering, 409 (1), art. no. 012028 ,

[23] T. Owa and T. Shinoda, TiAl surface coating on titanium by plasma transferred arc surfacing and its oxidation behavior, (2006) Materials Transactions, 47 (2), pp. 247-250.

[24] M. Tajoure and A. Tajouri, Characterization of Carbides Composite Surface Layers Produced By PTA, Conference: 4th International Congress in Advances in Applied Physics and Materials Science
(APMAS) Location: Fethiye, TURKEY Date: APR 24-27, 2014, 4TH INTERNATIONAL CONGRESS IN ADVANCES IN APPLIED PHYSICS AND MATERIALS SCIENCE (APMAS 2014) Book Series: AIP Conference Proceedings Volume: 1653 Article Number: 020099 Published: 2015, DOI: 10.1063/1.4914290

[25] E.N. Korosteleva, V.V. Korzhova and M.G. Krinitcyn, Sintering behavior and microstructure of TiC-Me composite powder prepared by SHS, (2017) Metals, 7 (8), art. no. 290

[26] V.E. Gromov, V.E. Kormyshev, A.M. Glezer, S.V. Konovalov, Y.F. Ivanov and A.P. Semin, Microstructure and wear properties of Hardox 450 steel surface modified by $\mathrm{Fe}-\mathrm{C}-\mathrm{Cr}-\mathrm{Nb}-\mathrm{W}$ powder wire surfacing and electron beam treatment, (2018) IOP Conference Series: Materials Science and Engineering, 411 (1), art. no. 012024,

[27] V.E. Kormyshev, V.E. Gromov, Y.F. Ivanov and S.V. Konovalov, Structure and properties of the wear-resistant facing modified by electron-beam processing, (2017) Uspehi Fiziki Metallov, 18 (2), pp. 111-139.

[28] Yu.F. Ivanov, A.I. Potekaev, E.A. Petrikova, E. A.; et al., Modification of the surface layer of the system coating ( $\mathrm{TiCuN}$ ) substrate (A7) by an intensive electron beam, Conference: International Scientific Conference on Radiation-Thermal Effects and Processes in Inorganic Materials Location: Tomsk, RUSSIA Date: NOV 03-08, 2014, INTERNATIONAL SCIENTIFIC CONFERENCE ON RADIATION-THERMAL EFFECTS AND PROCESSES IN INORGANIC MATERIALS Book Series: IOP Conference Series-Materials Science and Engineering Volume: 81 Article Number: 012009 Published: 2015, DOI: 10.1088/1757$899 X / 81 / 1 / 012009$

[29] P. Tashev, P. Petrov, S. Valkanov, G. Stefanov and E. Balabanova, „Electron Beam Surface Alloying of Low Carbon Steel in Presence of TiN, TiCN Nanopartic" Nanoscience \& Nanotechnology, Iss. 14, pp.183-187, (2014) ISSN 1313-8995

[30] J. Ju, Y. Zhou, M. Kang and J. Wang, Optimization of process parameters, microstructure, and properties of laser cladding febased alloy on 42CrMo steel roller, (2018) Materials, 11 (10), art. no. 2061 ,

[31] M.O. Ogunlana, E.T. Akinlabi, M.F. Erinosho et al., Integrated Experimental Approach for Alloying of Surface Layer Ti6Al4V+B4C Metal Matrix Composites using Laser Treatment MATERIALS RESEARCH-IBERO-AMERICAN JOURNAL OF MATERIALS Volume: 22 Issue: 2 Article Number: UNSP e20180368 Published: 2019

[32] S.E. Krylova, S.P. Oplesnin and M.I. Goltyapin, Influence of gas-powder laser cladding's technological parameters on structural characteristics of corrosion-resistant steels' restored surface layer Conference: 11th International Conference on Mechanical Engineering, Automation and Control Systems (MEACS) Location: Tomsk, RUSSIA Date: DEC 04-06, 2017 INTERNATIONAL CONFERENCE ON MECHANICAL ENGINEERING, AUTOMATION AND CONTROL SYSTEMS 2017 Book Series: IOP Conference Series-Materials Science and Engineering Volume: 327 Article Number: UNSP 042058 Published: 2018

[33] D. Janicki, Microstructure and Sliding Wear Behaviour of In-Situ TiC-Reinforced Composite Surface Layers Fabricated on Ductile Cast Iron by Laser Alloying, MATERIALS Volume: 11 Issue: 1 Article Number: 75 Published: JAN 2018

[34] A. Lisiecki, Mechanisms of hardness increase for composite surface layers during laser gas nitriding of the Ti6A14V alloy, MATERIALI IN TEHNOLOGIJE Volume: 51 Issue: 4 Pages: 577 583 Published: JUL-AUG 2017 DOI: 10.17222/mit.2016.106

[35] T. Yamaguchi, H. Hagino, Y. Michiyama, et al., Sliding Wear Properties of Ti/TiC Surface Composite Layer Formed by Laser Alloying, MATERIALS TRANSACTIONS Volume: 56 Issue: 3 Pages: 361-366 Published: 2015, DOI: 10.2320/matertrans. M2014330

[36] T. Yamaguchi, H. Hagino, M. Takemura, et al., Microstructure of MC-Fe Composite Layer on Carbon Steel by Laser Surface Alloying, JOURNAL OF LASER MICRO NANOENGINEERING Volume: 9 Issue: 2 Pages: 83-87 Published: JUN 2014, DOI: 10.2961/jlmn.2014.02.0001

[37] T. Yamaguchi, H. Hagino, M. Takemura, et al., Microstructure of Fe-TiC Composite Surface Layer on Carbon Steel Formed by Laser Alloying Process, MATERIALS TRANSACTIONS Volume: 54 Issue: 9 Pages: 1755-1759 Published: 2013, DOI: 10.2320/ matertrans.MAW201304

[38] S. Zherebtsov, K. Maekawa, T. Hayashi, et al., Laser surface alloying of SUS316 stainless steel with Al-Si - (Effect of substrate temperature on structure and properties of modified layer), Conference: JSME/ASME International Conference on Materials and Processing Location: Seattle, WA Date: JUN 19-22, 2005 ,Sponsor(s): JSME; ASME, JSME INTERNATIONAL JOURNAL SERIES A-SOLID MECHANICS AND MATERIAL ENGINEERING Volume: 48 Issue: 4 Pages: 292-298 Published: OCT 2005, DOI: 10.1299 /jsmea.48.292

[39] K. Uenishi and KF. Kobayashi, Formation of surface layer based 
on Al3Ti on aluminum by laser cladding and its compatibility with ceramics, INTERMETALLICS Volume: 7 Issue: 5 Pages: 553 559 Published: MAY 1999, DOI: 10.1016/S0966-9795(98)00071 5

[40] J.A. Kaleicheva and Z.K. Karaguiozova, Electroless composite nickel coatings strengthening with TiN nanoparticles plated on ductile cast iron, Materials Science Forum 919, pp. 52-58 https:// doi.org/10.4028/www.scientific.net/MSF.919.52

[41] J. Kaleicheva and Z. Karaguiozova, Improvement of the Wear Resistance of Ferrous Alloys by Electroless Plating of Nickel, IOP Conference Series: Materials Science and Engineering 295(1), 012036

[42] Z. Karaguiozova, J. Kaleicheva, V. Mishev and G. Nikolcheva, Enhancement in the tribological and mechanical properties of electroless Nickel-nanodiamond coatings plated on iron. Tribology in Industry, vol. 39, No 4, pp. 444-451, 2017, ISSN: 0354-8996

[43] J.C.Galvis, P.H.F. Oliveira, J. De Paula Martins, J. and A.L.M. De Carvalho, Assessment of process parameters by friction surfacing on the double layer deposition, (2018) Materials Research, 21 (3), art. no. 20180051
[44] R. Srinivasu, A. Sambasiva Rao, G. Madhusudhan Reddy and K. Srinivasa Rao, Friction stir surfacing of cast A356 aluminium-silicon alloy with boron carbide and molybdenum disulphide powders, (2015) Defence Technology, 11 (2), pp. 140-146.

[45] E. Mahmoud, M. Takahashi, T. Shibayanagi, et al., Fabrication of Surface-Hybrid-MMCs Layer on Aluminum Plate by Friction Stir Processing and Its Wear Characteristics, MATERIALS TRANSACTIONS Volume: 50 Issue: 7 Special Issue: SI Pages: 18241831 Published: JUL 2009, DOI: 10.2320/matertrans.M2009092

[46] Dema Ba, Fanjun Meng and Xiaoting Liu, Friction and wear behaviors of surface nanocrystalline layer prepared on medium manganese surfacing layer under oil lubrication, Tribology International 80 (2014) p. 210-215

[47] S. Hanke, A.Fischer and J.F.dos Santos, Sliding wea rbehaviour of a Cr-base alloy after microstructure alterations induced by friction surfacing, Wear 338-339 (2015) 332-338, https://doi. org/10.1016/j.wear.2015.07.010 